Cita bibliográfica: Shaadi Rodríguez, R.M.; Pulido Fernández, J.I. y Rodríguez Herrera, I.M. (2018). La consolidación turística en los territorios que conforman el Programa Pueblos Mágicos (México). Un análisis de sus estrategias competitivas. Investigaciones Turísticas (15), pp. 1-33. http://dx.doi.org/10.14198/INTURI2018.15.01

\title{
La consolidación turística en los territorios que conforman el Programa Pueblos Mágicos (México). Un análisis de sus estrategias competitivas
}

\author{
Tourism consolidation in the territories that form part of the Magic Towns Program \\ (Mexico). An analysis of their competitive strategies
}

Rosa María Shaadi Rodríguez. Universidad Autónoma de Aguascalientes, México. rossyshaadi@yahoo.com.mx Juan Ignacio Pulido Fernández. Universidad de Jaén, España. jipulido@ujaen.es Ismael Manuel Rodríguez Herrera. Universidad Autónoma de Aguascalientes, México. imrodri@correo.uaa.mx

\section{RESUMEN}

Esta investigación busca señalar la fase del ciclo de vida de localidades adscritas al Programa Pueblos Mágicos, identificando a aquéllas en consolidación, sus estrategias competitivas y los ámbitos con los que éstas se relacionan. La metodología se basó en el análisis de los estudios diagnósticos de la Secretaría de Turismo Federal para los Pueblos Mágicos en los que, por un lado, se identificaron variables de Competitividad y Sustentabilidad que aportarían información relativa a las características del ciclo de vida y, por otro, se analizaron los apartados de conclusiones, propuestas y proyectos de los mismos diagnósticos para identificar estrategias competitivas efectuadas por las localidades consolidadas. Los resultados revelan que de las localidades de la muestra, el menor porcentaje se encuentra en consolidación, mientras que la mayoría se ubican en etapa de desarrollo. De las estrategias competitivas generadas por los Pueblos Mágicos consolidados, la mayor parte de ellas guardan relación con los ámbitos de la Gestión, de los Recursos de Soporte y de los Recursos y Atractivos Esenciales. El desarrollo de estrategias enfocadas en factores clave, ha influido en la madurez de estos territorios, en busca de competitividad y posicionamiento en el sector turismo y de una mejor calidad de vida para sus residentes.

Palabras clave: ciclo de vida, destino turístico, Programa Federal, competitividad.

\section{ABSTRACT}

This research seeks to identify the phase of the life cycle of towns included in the Magic Towns Program of Mexico, identifying those in the consolidation stage and documenting the competitive strategies that have enabled them to become established as part of the Magic Town 
brand and distinguishing the areas with which these strategies are related. The methodology is based on the analysis of the diagnostic studies carried out by the Ministry of Federal Tourism for Magic Towns. This analysis first identifies the Competitiveness and Sustainability variables that provide information regarding the characteristics of each stage of the life cycle and, second, identifies competitive strategies carried out by the consolidated towns from the sections of conclusions, proposals and projects of the same diagnoses. The results reveal that of the sample towns, a small percentage is in consolidation, while the majority is in the development stage. Of the competitive strategies generated by the consolidated towns, most of them, in order of importance, are related to areas of Management, Support Resources and Resources and Essential Attractions. The development of strategies focused on key factors has influenced the maturity of these territories which seek to improve their competitiveness and positioning in the tourism sector and obtain a better quality of life for their residents.

Keywords: life cycle, tourist destination, Federal Program, competitiveness.

\section{INTRODUCCIÓN}

En los últimos años, la actividad turística ha mostrado un desarrollo tal que le ha permitido crecer de manera continua, por lo que muchos países han puesto su interés en ella como una acción por la que pueden obtenerse beneficios de diversa índole.

Al manifestar el turismo una estrecha relación con el desarrollo económico (OMT, 2017), a él se adhieren gran cantidad de comunidades receptoras que han descubierto la existencia en ellas de cualidades turísticas, con la finalidad de convertirse en nuevos destinos que funcionen como fuentes generadoras de ingresos, principalmente, como preservadores de identidad cultural y como renovadores del ambiente social de una colectividad.

Oyarzún y Szmulewicz (2009) señalan que la mejora constante en la calidad que se ofrece a los visitantes en los destinos turísticos es el inicio de una competitividad progresiva, la cual es un factor de consolidación para los mismos, es decir, un ingrediente que afianza su posición en el mercado turístico respecto a sus competidores y vigoriza su crecimiento y desarrollo.

Los destinos turísticos pueden estar inmersos, por un lado, en una variedad de tipologías que llegan a obedecer a distintos criterios y, por otro, en el apego a diferentes tendencias y al cumplimiento de políticas públicas, con lo cual se puede ver afectada la determinación e implementación de estrategias que impacten el crecimiento de su competitividad y, por ende, de su consolidación.

Pueblos Mágicos de México es uno de los programas que ha dado mayor reconocimiento a comunidades que presentan características propicias para la actividad turística y en el que los enfoques de innovación, diversificación y competitividad, al amparo de la sostenibilidad, se han visto atendidos mediante la implementación y operación de este programa federal.

La competitividad de un territorio con vocación turística, ya sea que actúe por sí mismo, es decir, a través de una gestión local independiente, o se encuentre inscrito dentro de algún programa gubernamental y se gestione en base a los lineamientos de este, como es el caso 
de las localidades Pueblos Mágicos, requiere del establecimiento de estrategias adecuadas para contribuir a su consolidación como destino y a un posicionamiento claro en la mente de los turistas. Estas estrategias deberán surgir de elementos pertenecientes a diferentes dimensiones o ámbitos y podrán ser un marco de desempeño mediante el cual se lograrán ordenar convenientemente los recursos con los que cuenta el lugar.

Con base en lo anterior, se establece la siguiente hipótesis de trabajo: "existen estrategias definidas en relación a diversos ámbitos que han influido en la consolidación de los Pueblos Mágicos como destinos turísticos".

El objetivo central de la investigación será identificar la fase del ciclo de vida en la que se encuentran las localidades y documentar las estrategias competitivas que han permitido a algunas de estas poblaciones mexicanas afianzarse como destinos bajo la marca Pueblo Mágico, distinguiendo con qué tipo de factores o ámbitos se relacionan dichas estrategias.

\section{MARCO TEÓRICO}

Actualmente, México ha ascendido a la novena posición en el ranking mundial respecto a recepción de visitantes (OMT, 2016), distinguiéndose, por ello, como uno de los líderes en el mercado mundial del turismo gracias a diversos factores positivos pero, a pesar de ello, el país aún carece de fortalecimiento en cuanto a la implementación de estrategias y acciones que le confieran valiosos índices de competitividad (Ibáñez, 2011; Rodríguez y Pulido, 2010).

La competitividad ha sido motivo de estudios reflexivos sobre diversos aspectos acerca de ella: su conceptualización y medición (Enright y Newton, 2005; González y Mendieta, 2009; Ibáñez, 2011), su relación con factores como la innovación (Puccio y Grana, 2008), la creatividad (García y Pulido, 2015) y la comercialización (Buhalis, 2000) o sobre propuestas teóricas existentes como modelos de competitividad de aplicación general (Jiménez, 2006; Porter, 1990; Ritchie y Crouch, 2003), de aplicación a destinos turísticos específicos (Dwyer y Kim, 2003; Jiménez y Aquino, 2012) o de generación de estrategias competitivas a partir de varios aspectos (Mazaro y Varzin, 2008).

Por otra parte, dado que la competitividad guarda también relación con elementos esenciales del campo del marketing, varias investigaciones analizan los efectos resultantes que enmarcan su asociación con el precio (Dwyer et al., 2000), la imagen (Andrades, Sánchez y Pulido, 2013; Muñoz, 2002; Pike, 2009), la marca (Ekinci y Hosany, 2006; Pike, 2009) y el posicionamiento (Gonçalves-Gândara et al., 2013). Estos elementos son importantes herramientas concernientes al crecimiento y progresión de esta capacidad: la competitividad, señalada por otros autores como una activadora de prosperidad social a través de su fortalecimiento (Crouch y Ritchie, 1999).

En la actualidad, se están produciendo cambios en las formas tradicionales de desarrollo y, debido a ello, evolucionan las metodologías y los procesos de planificación con la finalidad de atender el avance de los destinos con capacidad para abrirse un hueco frente a sus competidores (Ávila y Barrado, 2005). 
El ciclo de vida de los destinos turísticos también ha sido estudiado en cuanto a su relación con la diversidad competitiva que presentan estos sitios. Dentro del ciclo vida de un destino, cada etapa posee sus propias características (Soares et al., 2012), que requieren de un tratamiento adecuado mediante la implementación de estrategias apropiadas y efectivas que lleven al destino a un avance que determine ascenso, evitando el retroceso o estancamiento que pueda llevar al desvanecimiento de esfuerzos y logros anteriores o iniciales. El modelo del ciclo de vida de Butler(1980), es considerado, en su valor real, como una herramienta en la conceptualización de la dinámica de cambio de un destino turístico (Russell, 1995 en Digance, 1996) o como "un modelo descriptivo-predictivo" (Montaño et al., 2014, p.271) que ayude a diversificar la oferta (Pérez y Páez, 2014), planteando propuestas alternativas a los esquemas tradicionales con los que se maneja la actividad turística en un destino, de modo que pueda generarse en él consolidación, si aún no la tiene, revitalización, si está ya en esta fase, o reposicionamiento, si se encuentra en una etapa de declive (García, 2011; Vera, 1994; Vera y Baños, 2010).

En cuanto al Programa Pueblos Mágicos, se han realizado estudios relativos a la percepción y satisfacción que tienen los residentes en localidades con este nombramiento respecto a los efectos del turismo en su comunidad (Covarrubias, Vargas y Rodríguez, 2010), en relación a las consecuencias que, en general, este programa ha originado como producto de la política pública turística del gobierno federal (Loredo, 2012; Velázquez, 2013) o con referencia a la caracterización del producto turístico que ofrecen estas poblaciones, valorando los atributos que lo conforman y que pueden conceder competitividad a las mismas (Shaadi, Pulido y Rodríguez, 2016).

\subsection{Ciclo de vida del destino turístico}

\subsubsection{Destino turístico}

Valls (2004) señala que conceptualizar a un destino turístico implica reflexionar sobre una serie de particularidades que lo conforman y que sirven como fundamento al momento de delimitar lo qué es: espacio geográfico, centralidad, existencia de una oferta de servicios estructurada, una marca que identifique al destino y un trabajo integrado de mercadeo.

Con base en estas cinco conceptualizaciones, Valls (2004, pp.18-19) define al destino turístico como: "un espacio geográfico determinado, con rasgos propios de clima, raíces, infraestructuras y servicios y con cierta capacidad administrativa para desarrollar instrumentos comunes de planificación, que adquiere centralidad atrayendo a turistas mediante productos perfectamente estructurados y adaptados a las satisfacciones buscadas gracias a la puesta en valor y ordenación de los atractivos disponibles; dotado de una marca y que se comercializa teniendo en cuenta su carácter integral".

También es conveniente considerar los componentes de un destino, que, básicamente, son los recursos y los productos. Los primeros son el punto de partida para la creación de los segundos, por tanto es de importancia conocer aquellos recursos tangibles o intangibles que generen interés extra-local y planificar con ellos la conformación adecuada de productos 
turísticos atractivos que propicien, por un lado, satisfacción y experiencias específicas al usuario y, por otro, que otorguen "beneficios tales como la competitividad, la rentabilidad y el desarrollo sostenible" (Shaadi et al., 2017).

Siendo conformados los productos turísticos de manera armónica, complementaria y sistémica, el destino proyectará la perspectiva de una estructura sólida e integral que dará una ventaja competitiva al mismo.

Por tanto, en la planificación del destino deberá considerarse la generación de estrategias efectivas y adentrarse en un proceso de mejora continua de las mismas, realizándose las acciones de control pertinentes sobre lo planificado.

\subsubsection{Ciclo de vida}

Dado que tanto los componentes como la competitividad de los destinos turísticos se evalúan en relación a la existencia de estos mismos elementos en otros destinos competidores, es de relevancia identificar el impulso y progreso de los destinos turísticos en base al conocimiento de sus etapas o períodos de vida.

El modelo de ciclo de vida del destino turístico constituye uno de los temas de mayor importancia en el estudio de la competitividad turística, ya que muestra la evolución del destino en el tiempo, convirtiéndose en un instrumento de análisis que permite conocer la prosperidad turística de un destino a través de las llegadas periodificadas de visitantes (Butler, 1980). Su utilidad principal es facilitar la comprensión y el desarrollo de productos y destinos y proporcionar una guía para la toma de decisiones estratégicas (Buhalis, 2000).

Para ello, se identifican varias etapas que requieren acciones de planificación y gestión diferentes. Conociendo las características de la etapa en la que se encuentra un destino turístico, se podrán crear y establecer estrategias competitivas concretas y centradas en el avance del destino y en la oportunidad de generar su posicionamiento en el mercado internacional.

Aun cuando cada etapa tiene sus propias particularidades, debe tenerse en cuenta la existencia de distintos factores, externos e internos, que afectan al ciclo de vida de los destinos turísticos (Soares et al., 2012).

La Tabla 1 presenta, de manera sintética, las principales características de cada etapa, conforme a lo señalado por Butler (1980). 
Tabla 1. Delineación de las etapas del ciclo de vida de un destino turístico

\begin{tabular}{|c|c|c|}
\hline Exploración & Implicación & Desarrollo \\
\hline $\begin{array}{l}\text { - Mayoría de visitantes } \\
\text { ocasionales. } \\
\text { - No existen atractivos } \\
\text { diseñados como oferta } \\
\text { turística. } \\
\text { - Poca conectividad. }\end{array}$ & $\begin{array}{l}\text { - Comienzan a identificarse } \\
\text { los períodos de afluencia } \\
\text { turística. } \\
\text { - Llegadas de turistas } \\
\text { positivas, pero lentas. } \\
\text { - Comienza a formalizarse el } \\
\text { uso de atractivos. } \\
\text { - Los residentes comienzan a } \\
\text { participar en la provisión de } \\
\text { servicios. } \\
\text { - Comienzan a desarrollarse } \\
\text { vías de acceso. }\end{array}$ & $\begin{array}{l}\text { - La cantidad de turistas en } \\
\text { temporadas altas puede ser } \\
\text { igual o mayor a la población. } \\
\text { - Los atractivos se comercian } \\
\text { en específico y con mejores } \\
\text { instalaciones. } \\
\text { - Cambios perceptibles en la } \\
\text { apariencia física de la zona. } \\
\text { - Autoridades y empresarios } \\
\text { invierten intensamente en } \\
\text { publicidad. } \\
\text { - Crecimiento y mejora en la } \\
\text { accesibilidad. }\end{array}$ \\
\hline Consolidación & Estancamiento & Declive \\
\hline $\begin{array}{l}\text { - Se incrementan los } \\
\text { visitantes, pero disminuye } \\
\text { la tasa de crecimiento. } \\
\text { - Total de visitantes supera } \\
\text { al total de población } \\
\text { residente. } \\
\text { - Se conformaron productos } \\
\text { turísticos con los atractivos } \\
\text { turísticos del lugar. } \\
\text { - Parte de la economía local } \\
\text { está ligada al turismo. } \\
\text { - Se ofrecen servicios } \\
\text { turísticos a través de } \\
\text { franquicias y cadenas. } \\
\text { - Transformación favorable } \\
\text { de la imagen urbana. } \\
\text { - La publicidad es de amplio } \\
\text { alcance. } \\
\text { - Amplia conectividad. }\end{array}$ & $\begin{array}{l}\text { - Se alcanzó la afluencia } \\
\text { máxima de visitantes. } \\
\text { - Fuerte dependencia de } \\
\text { repetición de visitas o } \\
\text { de eventos que generen } \\
\text { afluencia. } \\
\text { - Los atractivos naturales y } \\
\text { culturales genuinos serán } \\
\text { sustituidos por instalaciones } \\
\text { “artificiales". } \\
\text { - Se habrán excedido niveles } \\
\text { de capacidad en diversas } \\
\text { variables, creando diferentes } \\
\text { problemas. } \\
\text { - Habrá excedentes en oferta } \\
\text { de cuartos. } \\
\text { - La imagen urbana será } \\
\text { compleja. } \\
\text { - Imagen bien posicionada } \\
\text { pero que ya no estará de } \\
\text { moda. }\end{array}$ & $\begin{array}{l}\text { - Ya no se atraerá a los turistas; } \\
\text { el destino se utilizará cada } \\
\text { vez más para fin de semana o } \\
\text { viajes de un día. } \\
\text { - La zona no será capaz de } \\
\text { competir con los nuevos } \\
\text { atractivos. } \\
\text { - Se enfrentará a un mercado en } \\
\text { retroceso. } \\
\text { - Desaparición de instalaciones } \\
\text { turísticas que hacen menos } \\
\text { atractivo al destino. } \\
\text { - Puede darse una declinación } \\
\text { paulatina hasta llegar al } \\
\text { declive total o puede darse } \\
\text { una estabilización que lleve a } \\
\text { un crecimiento inducido hasta } \\
\text { llegar a un rejuvenecimiento. }\end{array}$ \\
\hline
\end{tabular}

Fuente: Elaboración propia a partir de Butler (1980).

Butler (1980) representa en un gráfico (Figura 1) las etapas del ciclo de vida de un destino turístico, tomando como puntos de relación el número de turistas que lo visitan con respecto al tiempo transcurrido para el lugar. 
Figura 1. Modelo de ciclo de vida de un destino turístico

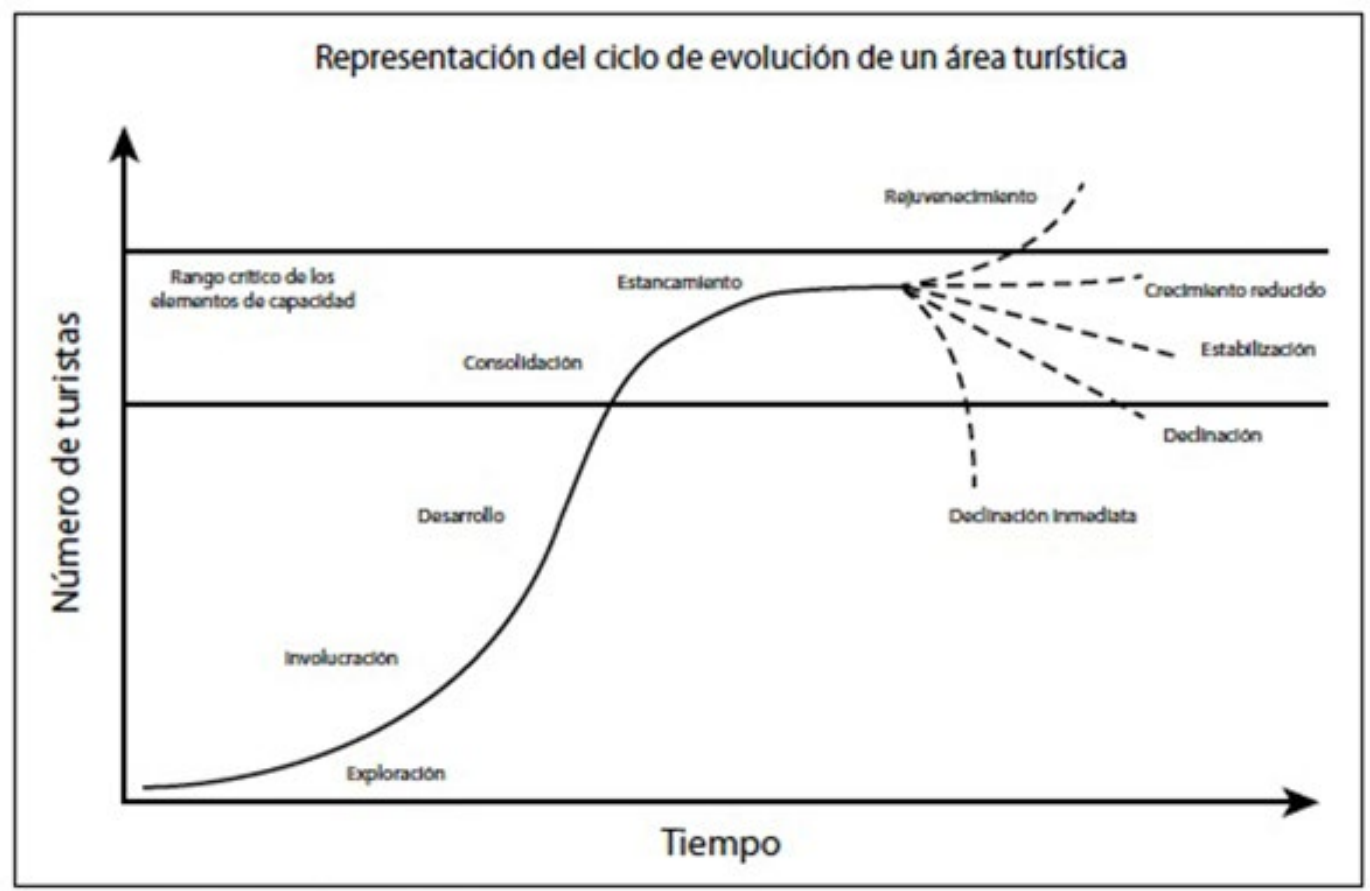

Fuente: Butler (1980).

Como plantean Soares et al. (2012, p.23), "un aumento en ambas direcciones genera la reducción general en la calidad y atracción cuando se superen los niveles de capacidad".

En relación a la integración de este modelo, que tiene un enfoque en el producto, con otras teorías, se han elaborado propuestas que plantean integrarlo al modelo teleológico, es decir, a un enfoque en la estrategia, para que, partiéndose del conocimiento de la etapa en la que se encuentra el destino, se pueda llegar a concebir sostenibilidad en él, a través de la implementación de estrategias que contribuyan a generar su competitividad en el mercado turístico (Oreja et al., 2008).

Es de importancia señalar que la falta de datos e información pueden ser una causa que limite el mejor uso de este modelo como herramienta predictiva del desarrollo del destino, así como la identificación de otros factores que hacen que los destinos no puedan ser valorados en apego a este modelo de ciclo de vida (Soares et al., 2012).

\subsection{Modelos de competitividad de los destinos turísticos}

El concepto de competitividad es complejo, subjetivo y de carácter multidimensional (Jiménez y Aquino, 2012). Su aplicación a empresas u organizaciones puede ser de mayor objetividad que si se aplica a países, lugares o a destinos inmersos en la actividad turística.

El análisis de la competitividad tiene sus fundamentos en la teoría económica clásica, evolucionando en sus enfoques hasta llegar a las importantes aportaciones de Porter (1980) sobre su teoría de la competitividad estructural, para la industria, y apoyada en el concepto 
de ventaja competitiva y más adelante su propuesta del diamante de la competitividad, en 1990, pensado para países. Como señala Pedro (2015, p.35), "la obra de Porter ha estado centrada, principalmente, en la industria, aunque algunos conceptos han sido útiles también en el mundo del turismo".

Desde entonces, una diversidad de aportaciones permite visualizar cómo ha evolucionado el estado del arte acerca de la competitividad respecto a teorías, definiciones, metodologías y modelos.

Siendo la competitividad un concepto relativo y difícil de medirse, se han generado algunas definiciones que permiten conformar una conceptualización sobre ella y su importancia, las cuales se recogen en la Tabla 2.

Tabla 2. Definiciones sobre competitividad

\begin{tabular}{|l|l|}
\hline \multicolumn{1}{|c|}{ Autor } & \multicolumn{1}{c|}{ Definición } \\
\hline Ritchie y Crouch (2000) & $\begin{array}{l}\text { Capacidad de un país para crear valor añadido e incrementar el bienestar } \\
\text { nacional, mediante la gestión de ventajas y procesos atractivos, } \\
\text { agresividad y proximidad, integrando las relaciones entre los mismos en } \\
\text { un modelo económico y social. }\end{array}$ \\
\hline Porter (2003) & $\begin{array}{l}\text { Surge de la productividad con la que las empresas emplean en una } \\
\text { ubicación sus recursos naturales, humanos y de capital para producir } \\
\text { bienes y servicios valiosos. }\end{array}$ \\
\hline Puccio y Grana (2008) & $\begin{array}{l}\text { Capacidad que tiene una empresa o territorio para insertarse en nuevos } \\
\text { mercados al tiempo que conserva las cuotas de mercado obtenidas } \\
\text { en el pasado, en forma eficaz, alcanzando con ello un aumento de } \\
\text { productividad y la rentabilidad. }\end{array}$ \\
\hline
\end{tabular}

Elaboración propia.

Definiciones y conceptualizaciones diversas de competitividad han dado pié a la creación de modelos de competitividad en los que se realizan propuestas para resaltar la relación de interdependencia entre elementos o la influencia de factores y variables que afectan o benefician la eficacia de acciones llevadas a cabo con la finalidad de alcanzar objetivos planteados.

El entorno global actual ha provocado que los mercados en los que se comercializan los productos y servicios sean cada vez más indeterminados y cambiantes, por lo que es necesaria la existencia de un modelo que se convierta en directriz hacia la efectividad.

Partiendo del modelo de competitividad de Porter (1990), algunos autores han propuesto modelos de competitividad diseñados pensando en su aplicación dentro del ámbito turístico: en empresas, productos o un destino. La Tabla 3 muestra las dimensiones, ámbitos o factores que convienen ser considerados conforme a algunos de los principales modelos de competitividad, propuestos para su aplicación al turismo. 
Tabla 3. Dimensiones, ámbitos o factores en modelos de competitividad turística

\begin{tabular}{|c|l|l|}
\hline Autor & \multicolumn{1}{|c|}{ Modelo } & \multicolumn{1}{c|}{ Dimensiones, ámbitos o factores } \\
\hline Bosch (1998) & $\begin{array}{l}\text { De desarrollo turístico e } \\
\text { impactos ambientales: las } \\
\text { nuevas coordenadas }\end{array}$ & $\begin{array}{l}\text { Consumidores, la tecnología, la producción y la } \\
\text { gestión de destinos turísticos. }\end{array}$ \\
\hline $\begin{array}{c}\text { Gennest y } \\
\text { Legg (2003) }\end{array}$ & $\begin{array}{l}\text { Clasificación de } \\
\text { Destinos Turísticos } \\
\text { (Premier Ranking) }\end{array}$ & $\begin{array}{l}\text { Recursos y atractivos esenciales, calidad y } \\
\text { masa crítica, satisfacción y valor, accesibilidad, } \\
\text { equipamientos y servicios; ocupación y } \\
\text { rentabilidad, reconocimiento crítico e imagen; } \\
\text { marketing; innovación y renovación, y } \\
\text { sustentabilidad local. }\end{array}$ \\
\hline $\begin{array}{c}\text { Dwyer y Kim } \\
\text { (2003) }\end{array}$ & $\begin{array}{l}\text { Integrado de competitividad } \\
\text { de un destino turístico }\end{array}$ & $\begin{array}{l}\text { Recursos: creados, heredados, generales, } \\
\text { intangibles. } \\
\text { Entorno: geográfico, económico, político, } \\
\text { mercadológico. Competitividad Turística. }\end{array}$ \\
\hline $\begin{array}{c}\text { Ritchie y } \\
\text { Crouch (2000 } \\
\text { y 2003) }\end{array}$ & Competitividad de Destinos & $\begin{array}{l}\text { Recursos innatos y atractivos esenciales; } \\
\text { recursos de soporte; administración del } \\
\text { destino; planeación y desarrollo; calificadores y } \\
\text { potenciadores determinantes. }\end{array}$ \\
\hline $\begin{array}{c}\text { Foro } \\
\text { Económico } \\
\begin{array}{c}\text { Mundial } \\
\text { (2007) }\end{array}\end{array}$ & $\begin{array}{l}\text { Índice de Competitividad de } \\
\text { Turismo y Viajes }\end{array}$ & $\begin{array}{l}\text { Competitividad de precios, factor humano, } \\
\text { tecnología, infraestructura, medioambiente, } \\
\text { desarrollo social. }\end{array}$ \\
\hline
\end{tabular}

Fuente: Elaboración propia a partir de Mazaro (2007), Amaya, Conde y Covarrubias (2008) y Jiménez y Aquino (2012).

Estos modelos son, de una u otra manera, "interpretaciones del sistema turístico" (Mazaro, 2007, p.1) orientados a la generación de impactos positivos en los destinos, beneficios y satisfacción para los turistas y desarrollo con fines sustentables, en la mira de una competitividad sostenida.

\subsection{Estrategias competitivas}

Diversas definiciones de estrategia se han aportado al paso del tiempo, permitiendo conceptualizar a ésta como una acción bien definida enfocada al logro de uno o varios objetivos establecidos en un proceso de planificación generado ya sea por entes públicos o privados.

La efectividad en el alcance de los objetivos planteados es indicio de que prevalece una gestión adecuada de recursos, procesos y personal, dirigida a conquistar competitividad para un producto, para una empresa, para un lugar y, en ello, el diseño e implementación de estrategias apropiadas es un requisito necesario para la obtención de resultados favorables relativos a conseguirla.

Los modelos de competitividad turística existentes presentan una coordinación y dependencia entre los factores o ámbitos que los componen, en base a los cuales pueden 
desarrollarse estrategias que marcarán, por un lado, la forma precisa y adecuada de actuación y, por otro, un fundamento para implantar controles que permitan juzgar el desempeño realizado y valorar y evaluar los éxitos o fracasos obtenidos en referencia a lo inicialmente planeado.

Ante los retos de la globalización, los desafíos para un destino turístico son mayores y continuos, por lo que Kotler (1994), con la frase "pensar globalmente, actuar localmente", propone tácitamente la creación y uso de estrategias dirigidas a efectuarse en ambas esferas, de manera que la competitividad que con ellas se logre contribuya a la consolidación del destino.

Oyarzún y Szmulewicz (2009, p.93) señalan que, "frente a un escenario económico cambiante, las estrategias competitivas exigen sensibilidad hacia el mercado local, visión internacional, velocidad para reaccionar (flexibilidad en la planificación), capacidad para aprender y actuar y sobre todo mayor innovación, la cual requiere implicación de los directivos en la realidad productiva y aumentar los recursos propios a través de alianzas con cooperadores y competidores".

Las estrategias para un destino turístico deben ser diseñadas e implementadas con la perspectiva de lograr para éste la competitividad y el posicionamiento que lo lleven a consolidar su existencia en el mercado y a ofrecer a los turistas o usuarios la calidad que de él se demanda.

\section{DISEÑO DE LA INVESTIGACIÓN}

\subsection{El Programa Pueblos Mágicos de México}

Para hacer frente a los retos actuales de competitividad, la diversificación ha sido utilizada como una estrategia que permita a muchos destinos turísticos vencer este desafío. Mediante la creación del Programa Pueblos Mágicos de México, la Secretaría de Turismo Federal, ha intentado "(...) revalorar a un conjunto de poblaciones del país (...)" (SECTUR, 2001, p.1), rescatando y reconociendo la cultura, historia y cotidianidad social que se mantiene viva en ellas.

Durante 2014, esta dependencia federal actualizó los lineamientos existentes, para sistematizar de manera clara y transparente el procedimiento de incorporación y permanencia de localidades en el Programa Pueblos Mágicos de México. Lo anterior fue realizado “(...) para una mejor optimización de recursos con proyectos que permitan la atracción de nuevos mercados y la generación de un mayor flujo de visitantes en las mismas, mediante la preservación de su identidad" (SECTUR, 2014a, p.3).

Las localidades que se encuentran adscritas a este programa federal poseen, a través de él, una categoría que las identifica como elementos diversificadores de la oferta turística del país. 


\subsection{Planteamiento metodológico}

Esta investigación es un estudio con alcance de tipo descriptivo en la que se pretende identificar estrategias competitivas similares que han permitido a localidades mexicanas lograr una consolidación como destinos bajo la marca Pueblo Mágico, señalando, a su vez, con qué tipo de dimensiones de modelos de competitividad turísticad guardan relación.

El diseño metodológico establecido es de tipo no experimental, ya que la información se obtiene en fuentes secundarias sobre las características principales del ciclo de vida de las localidades de la muestra y de las estrategias que se han utilizado para lograr la etapa de consolidación en algunas de ellas, para después analizarla en base a la metodología que se describe posteriormente. El estudio presenta un diseño transversal de tipo exploratorio y descriptivo, ya que la información se indagará en un solo momento de la investigación.

\subsection{Determinación de la muestra y recolección de datos}

La unidad de análisis son las localidades Pueblo Mágico, incorporadas al Programa por la Secretaría de Turismo Federal (SECTUR). La población considerada para el estudio son las $83^{1}$ localidades que habían sido inscritas en este programa hasta antes del 25 de septiembre de 2015. Se trabajó con una muestra probabilística aleatoria estratificada, de modo que todas las poblaciones con este nombramiento tuvieran igualdad de oportunidad para ser elegidas, utilizándose como estratos las cinco regiones (Norte, Pacífico, Golfo, Centro y Sur) en las que la SECTUR, hasta 2013, había dividido al territorio nacional, para que las poblaciones pudiesen ser ubicadas con mayor exactitud. Con un error máximo del $10 \%$ y un nivel deseado de confianza del $90 \%$, tomándose la muestra de las 83 localidades de la población, ésta se determinó utilizando el programa STATS y su selección aleatoria se efectuó también por medio de dicho programa.

Los Diagnósticos de Competitividad y Sustentabilidad de los Pueblos Mágicos (SECTUR, 2014b) fueron la principal fuente secundaria consultada, ya que contienen la información suficiente y actualizada para lograr el objetivo central de esta investigación, al ser documentos generados por la Secretaría de Turismo del Gobierno Federal (SECTUR) como una acción en apego a la Estrategia 4.11.2 del Plan Nacional de Desarrollo (PND) "Impulsar la innovación de la oferta y elevar la competitividad del sector turístico" y en relación a la línea de acción "Diversificar e innovar la oferta de productos y consolidar destinos" (PND 2013-2018, p.143). Estos documentos cuentan con validez científica, ya que el diseño de estos estudios fue una investigación descriptiva no experimental y transeccional, llevada a cabo con el involucramiento de los Gobiernos Estatales y autoridades locales responsables de la conducción del sector, así como de la participación de diversas Instituciones de Educación Superior, para asegurar la calidad de los estudios. Los Diagnósticos de Competitividad y Sustentabilidad se elaboraron en base a la metodología indicada por la SECTUR, en la cual se solicitó el estudio de 61variables agrupadas en dos dimensiones: competitividad y sustentabilidad, que, a su vez, se subdividían en sus respectivas áreas de atención:

1. En este trabajo, no se consideran como parte de la población los 28 municipios que fueron inscritos al Programa Pueblos Mágicos el 25 de septiembre de 2015, ya que, debido a su reciente incorporación al programa, se carece de información sobre ellos respecto al objetivo de investigación de este estudio. 
La consolidación turística en los territorios que conforman el Programa Pueblos Mágicos (México). Un análisis de sus estrategias competitivas

\begin{tabular}{|c|l|l|}
\hline Dimensiones & \multicolumn{2}{|c|}{ Áreas de atención } \\
\hline Competitividad & $\begin{array}{l}\text { Generales del destino, Demanda } \\
\text { Turística, } \\
\text { Oferta turística, Gestión turística. }\end{array}$ & $\begin{array}{l}\text { Infraestructura, Servicios, Recursos } \\
\text { Naturales y Culturales, Profesionalización. }\end{array}$ \\
\hline Sustentabilidad & $\begin{array}{l}\text { Agua, Desechos, Beneficios } \\
\text { Económicos del Turismo, Impacto } \\
\text { Social. }\end{array}$ & $\begin{array}{l}\text { Demanda Turística, Oferta Turística, } \\
\text { Planeación urbana y ambiental, } \\
\text { Desarrollo urbano integral e } \\
\text { Imagen urbana. }\end{array}$ \\
\hline
\end{tabular}

Para el análisis de las variables señaladas, se utilizaron como técnicas de recolección de datos: obtención directa de entes federales, estatales y municipales; revisión documental en Cámaras, Asociaciones, y Archivos Estatales y Municipales; entrevistas a empresarios locales; encuestas a visitantes; grupos de enfoque y foros de consulta. Posteriormente se realizó el análisis de la información cuantitativa y cualitativa obtenida, mediante estadística descriptiva, establecimiento de índices, análisis FODA, trabajo descriptivo e identificación de proyectos y programas, concretándose los resultados en los "Diagnósticos de Competitividad y Sustentabilidad de los Pueblos Mágicos".

\subsection{Metodología}

Para conformar la caracterización de las etapas del ciclo de vida de las localidades objeto de estudio, primeramente, se llevó a cabo la recolección de los Diagnósticos sobre Competitividad y Sustentabilidad de los Pueblos Mágicos de la muestra.

Posteriormente, se seleccionaron las áreas de atención de cada una de las dos dimensiones de los diagnósticos, que al ser analizadas, aportarían información relativa a las características delineadas en la revisión de la literatura (Tabla 1) para cada etapa del ciclo de vida de un destino turístico:

- Competitividad: Generales del destino, Demanda Turística, Oferta turística, Gestión turística, Infraestructura, Servicios, Recursos Naturales y Culturales y Profesionalización.

- Sustentabilidad: Beneficios Económicos del Turismo, Demanda Turística, Oferta Turística, Planeación urbana y ambiental, Desarrollo urbano integral e Imagen urbana.

Es importante señalar que, aunque las instituciones de Educación Superior utilizaron una metodología unificada para la elaboración de estos documentos, el contenido y la composición de la información fue presentada de acuerdo a los datos existentes y conforme a la manera particular de redactar de quienes elaboraron los informes. Por tanto, la labor de análisis de la información consultada en los diagnósticos, fue exhaustiva y razonada, por parte de quienes realizaron el presente estudio, de modo tal que, al identificar las características que definieran la etapa de ciclo de vida de cada localidad, éstas fueran delimitadas lo más cercano posible a la realidad. 
Con base en la información analizada se perfilaron las características del ciclo de vida de cada territorio, a partir de las características delineadas por Butler (1980) (Tabla 1), enmarcando lo anterior, en tablas por año de inscripción al programa y ubicándose las localidades de la muestra por región.

Posteriormente, con base en los resultados de las tablas, se realizó un análisis obteniendo porcentajes que permitieran conocer las fases del ciclo de vida existentes respecto de las localidades y cómo se presentaron los resultados por región.

Seguidamente, se elaboró una tabla en la que se enlistaron los municipios de la muestra detectados en fase de consolidación, las estrategias que cada uno de ellos ha generado para lograr afianzarse en esta etapa de vida y el ámbito o dimensión al que corresponden éstas.

La identificación de las estrategias se realizó mediante el análisis de los apartados de conclusiones, propuestas y portafolio de proyectos, ubicados dentro de los mismos Diagnósticos de Competitividad y Sustentabilidad de los Pueblos Mágicos (SECTUR, 2014b). De los ámbitos, dimensiones o factores que la revisión de la literatura plantea en los modelos de competitividad turística, fueron seleccionadas las 10 dimensiones que, en común, manejan estos modelos y en las que se ubicaron las estrategias competitivas de estos destinos consolidados: Gestión, Atractivos esenciales, Factor humano, Tecnología, Marketing Mix, Consumidores (turistas), Rentabilidad, Sostenibilidad, Investigación, Recursos de soporte (infraestructuras).

Por último, con base en los resultados concentrados en la tabla, se muestran gráficamente las dimensiones o ámbitos en los que mayormente se centra el desarrollo de estrategias para los Pueblos Mágicos reconocidos en etapa de consolidación.

\section{RESULTADOS Y DISCUSIÓN}

\subsection{Ciclo de vida en los Pueblos Mágicos}

Las Tablas 4 a 11 recogen los resultados sobre la fase del ciclo de vida de los Pueblos Mágicos de México que conformaron la muestra. 
Tabla 4. Ciclo de vida de pueblos mágicos inscritos en 2002

\begin{tabular}{|c|c|c|}
\hline Localidad & Fase & Características \\
\hline \multicolumn{3}{|r|}{ Pacífico } \\
\hline $\begin{array}{l}\text { Pátzcuaro, } \\
\text { Michoacán }\end{array}$ & Consolidación & \multirow[b]{2}{*}{$\begin{array}{l}\text { - Alta afluencia de visitantes en el año. } \\
\text { - Incremento de afluencia de turistas en temporadas } \\
\text { altas. } \\
\text { - Existencia de atractivos turísticos naturales y } \\
\text { culturales. } \\
\text { - Conformación de productos turísticos como rutas o } \\
\text { circuitos. } \\
\text { - El turismo contribuye a la economía local. } \\
\text { - Empresas turísticas locales y de cadena. } \\
\text { - Suficiencia de servicios públicos. } \\
\text { - Existen prácticas de sustentabilidad. } \\
\text { - Publicidad digital y de alcance. } \\
\text { - Alto grado de satisfacción del visitante. }\end{array}$} \\
\hline Taxco, Guerrero & Consolidación & \\
\hline \multicolumn{3}{|r|}{ Centro } \\
\hline $\begin{array}{l}\text { Dolores Hidalgo, } \\
\text { Guanajuato }\end{array}$ & Consolidación & $\begin{array}{l}\text { - Incremento en afluencia de visitantes, en } \\
\text { temporadas altas. } \\
\text { - Gestión de recursos turísticos e innovación en } \\
\text { actividades turísticas. } \\
\text { - Desarrollo de productos turísticos. } \\
\text { - Existencia de empresas turísticas locales y de } \\
\text { cadena. } \\
\text { - Suficiencia de servicios públicos. } \\
\text { - Existencia de conectividad terrestre y aérea } \\
\text { complementaria. } \\
\text { - Existen prácticas de sustentabilidad. } \\
\text { - Publicidad digital y de alcance. }\end{array}$ \\
\hline Cuetzalan, Puebla & Desarrollo & $\begin{array}{l}\text { - Cantidad elevada de turistas en temporadas altas. } \\
\text { - Generación de pequeños productos turísticos. } \\
\text { - Existencia de prestadores de servicios turísticos } \\
\text { básicos. } \\
\text { - Mejores instalaciones en atractivos. } \\
\text { - Cambios perceptibles en la apariencia física de la } \\
\text { zona. } \\
\text { - Publicidad incipiente. }\end{array}$ \\
\hline \multicolumn{3}{|r|}{ Sur } \\
\hline Izamal, Yucatán & \multicolumn{2}{|c|}{ No identificada por falta de información suficiente. } \\
\hline
\end{tabular}

Fuente: Elaboración propia a partir de SECTUR (2014b). 
Tabla 5. Ciclo de vida de pueblos mágicos inscritos en 2004

\begin{tabular}{|c|c|c|}
\hline Localidad & Fase & Características \\
\hline \multicolumn{3}{|r|}{ Norte } \\
\hline Parras, Coahuila & Desarrollo & $\begin{array}{l}\text { - Cantidad de visitantes en temporada alta mayor al } \\
\text { total de la población. } \\
\text { - Existe inventario de atractivos turísticos. } \\
\text { - Existen empresas turísticas locales y de cadena. } \\
\text { - Suficiencia de servicios públicos. } \\
\text { - Publicidad incipiente. } \\
\text { - Renovación de imagen urbana. }\end{array}$ \\
\hline
\end{tabular}

Fuente: Elaboración propia a partir de SECTUR (2014b).

Tabla 6. Ciclo de vida de pueblos mágicos inscritos en 2005

\begin{tabular}{|c|c|c|}
\hline Localidad & Fase & Características \\
\hline \multicolumn{3}{|r|}{ Norte } \\
\hline Cosalá, Sinaloa & Desarrollo & \multirow{2}{*}{$\begin{array}{l}\text { - Alta afluencia de visitantes. } \\
\text { - Variedad de atractivos generadores de distintos } \\
\text { tipos de turismo. } \\
\text { - Muy buena satisfacción del turista. } \\
\text { - Existen suficientes empresas de servicios turísticos. } \\
\text { - Suficiencia de servicios públicos. } \\
\text { - Perceptibles cambios en la imagen urbana. } \\
\text { - Publicidad digital. } \\
\text { - Se genera empleo en el sector turístico. }\end{array}$} \\
\hline Álamos, Sonora & Desarrollo & \\
\hline \multicolumn{3}{|r|}{ Pacífico } \\
\hline $\begin{array}{l}\text { Tlalpujahua, } \\
\text { Michoacán }\end{array}$ & Implicación & $\begin{array}{l}\text { - Visitas positivas pero lentas. } \\
\text { - Buenas instalaciones en atractivos, pero reducida } \\
\text { cantidad de ellos. } \\
\text { - Cambios perceptibles en la zona. } \\
\text { - Publicidad y conectividad medias y en crecimiento. } \\
\text { - No hay datos sobre satisfacción del visitante, ni } \\
\text { sobre empleo turístico. } \\
\text { - Suficiencia local en la oferta de servicios turísticos. }\end{array}$ \\
\hline \multicolumn{3}{|r|}{ Centro } \\
\hline $\begin{array}{l}\text { Bernal, } \\
\text { Querétaro }\end{array}$ & Desarrollo & $\begin{array}{l}\text { - Cantidad elevada de turistas en temporadas altas. } \\
\text { - Mejores instalaciones en atractivos, pero reducida } \\
\text { cantidad de ellos } \\
\text { - Cambios perceptibles en la zona. } \\
\text { - Publicidad media y en crecimiento. } \\
\text { - No hay datos sobre satisfacción del visitante. } \\
\text { - Conectividad media. } \\
\text { - Suficiencia local en la oferta de servicios turísticos. }\end{array}$ \\
\hline
\end{tabular}

Fuente: Elaboración propia a partir de SECTUR (2014b). 
Tabla 7. Ciclo de vida de pueblos mágicos inscritos en 2006

\begin{tabular}{|c|c|c|}
\hline Localidad & Fase & Características \\
\hline \multicolumn{3}{|r|}{ Norte } \\
\hline $\begin{array}{l}\text { Todos Santos, } \\
\text { Baja California } \\
\text { Sur }\end{array}$ & Desarrollo & $\begin{array}{l}\text { - Buena y continua afluencia de turistas. } \\
\text { - Mayor porcentaje de turistas extranjeros. } \\
\text { - Conservación media de recursos. } \\
\text { - Existe inventario de recursos turísticos, pero sin } \\
\text { cartera amplia y diversificada de actividades. } \\
\text { - Suficiente oferta de servicios turísticos. } \\
\text { - Buena conectividad. } \\
\text { - Inicia publicidad digital. } \\
\text { - Satisfacción regular del visitante. }\end{array}$ \\
\hline \multicolumn{3}{|r|}{ Pacífico } \\
\hline $\begin{array}{l}\text { Cuitzeo, } \\
\text { Michoacán }\end{array}$ & Desarrollo & $\begin{array}{l}\text { - Existe inventario de recursos turísticos y programas } \\
\text { de conservación. } \\
\text { - Conectividad media. } \\
\text { - Suficiente planta de servicios turísticos. } \\
\text { - Alto grado de satisfacción del visitante. } \\
\text { - Cambios favorables en la imagen urbana. }\end{array}$ \\
\hline \multicolumn{3}{|r|}{ Centro } \\
\hline $\begin{array}{l}\text { Real de Asientos, } \\
\text { Aguascalientes }\end{array}$ & Implicación & $\begin{array}{l}\text { - Buena cantidad de turistas sólo en temporadas } \\
\text { altas. } \\
\text { - No hay inventario de recursos. } \\
\text { - Buen grado de conservación de los atractivos. } \\
\text { - Los atractivos se comercializan específicamente y } \\
\text { cuentan con instalaciones. } \\
\text { - Cambios perceptibles en la apariencia física del } \\
\text { lugar. } \\
\text { - Comienza a generarse empleo turístico. } \\
\text { - Muy limitada oferta de servicios turísticos. } \\
\text { - Incipiente conectividad. }\end{array}$ \\
\hline
\end{tabular}

Fuente: Elaboración propia a partir de SECTUR (2014b). 
Tabla 8. Ciclo de vida de pueblos mágicos inscritos en 2007

\begin{tabular}{|c|c|c|}
\hline Localidad & Fase & Características \\
\hline \multicolumn{3}{|r|}{ Norte } \\
\hline Creel, Chihuahua & Desarrollo & $\begin{array}{l}\text { - Certificaciones en guianza } \\
\text { - Seguridad para el turista. } \\
\text { - Prevalecen atractivos naturales. } \\
\text { - Suficiente oferta de servicios turísticos. } \\
\text { - Publicidad digital } \\
\text { - Prácticas de sustentabilidad. } \\
\text { - Generación de empleo turístico. } \\
\text { - Programas de mejora urbana en proceso. } \\
\text { - Aumento de conectividad en proceso. }\end{array}$ \\
\hline \multicolumn{3}{|r|}{ Golfo } \\
\hline Mier, Tamaulipas & Implicación & $\begin{array}{l}\text { - Existe inventario de atractivos turísticos con poca } \\
\text { oferta. } \\
\text { - Conservación media de recursos turísticos. } \\
\text { - Poca oferta de servicios turísticos. } \\
\text { - Poca conectividad. } \\
\text { - No hay datos sobre empleo turístico. } \\
\text { - No existe publicidad que genere una imagen } \\
\text { atrayente del sitio. }\end{array}$ \\
\hline \multicolumn{3}{|r|}{ Pacífico } \\
\hline $\begin{array}{l}\text { Capulálpam, } \\
\text { Oaxaca }\end{array}$ & Implicación & $\begin{array}{l}\text { Poca estacionalidad, pero con afluencia de visitantes. } \\
\text { Existen atractivos naturales bien conservados. } \\
\text { Conectividad incipiente. } \\
\text { Reducida oferta de servicios turísticos. } \\
\text { Buena seguridad pública. } \\
\text { Prácticas ambientales. } \\
\text { Se genera poco empleo en el sector. } \\
\text { No existe publicidad de alcance. }\end{array}$ \\
\hline \multicolumn{3}{|r|}{ Centro } \\
\hline $\begin{array}{l}\text { Huamantla, } \\
\text { Tlaxcala }\end{array}$ & Desarrollo & $\begin{array}{l}\text { - En temporada alta, afluencia de visitantes } \\
\text { nacionales y en menor porcentaje de extranjeros. } \\
\text { - Existen recursos de gran atractivo cultural. } \\
\text { - Cuenta con buena conectividad terrestre. } \\
\text { - Existencia suficiencia de empresas prestadoras de } \\
\text { servicios turísticos. } \\
\text { - Buena imagen urbana. } \\
\text { - Uso de las tecnologías para la publicidad del lugar. } \\
\text { - Existe contribución del turismo a la economía local. }\end{array}$ \\
\hline
\end{tabular}




\begin{tabular}{|c|c|c|}
\hline Jerez, Zacatecas & Implicación & $\begin{array}{l}\text { - Existe suficiente conectividad terrestre. } \\
\text { - Abundancia de recursos de tipo cultural, pero sin } \\
\text { uso turístico por medio de actividades. } \\
\text { - Promoción insuficiente. } \\
\text { - Reducida oferta de servicios turísticos y carentes de } \\
\text { calidad. } \\
\text { - No hay programas de mejora urbana. } \\
\text { - Poca seguridad pública. } \\
\text { - No existen prácticas sustentables. } \\
\text { - Baja estacionalidad. }\end{array}$ \\
\hline
\end{tabular}

Fuente: Elaboración propia a partir de SECTUR (2014b).

Tabla 9. Ciclo de vida de pueblos mágicos inscritos en 2010

\begin{tabular}{|c|c|c|}
\hline Localidad & Fase & Características \\
\hline \multicolumn{3}{|r|}{ Golfo } \\
\hline $\begin{array}{l}\text { Tapijulapa, } \\
\text { Tabasco }\end{array}$ & Implicación & $\begin{array}{l}\text { - Llegadas de visitantes positivas pero lentas. } \\
\text { - Predominan actividades y atractivos turísticos } \\
\text { naturales, sobre actividades y recursos de tipo } \\
\text { cultural. } \\
\text { - Buena conectividad terrestre pero carente de } \\
\text { señalética adecuada. } \\
\text { - Estructura turística pequeña, local y escasa, e } \\
\text { incongruente con los atractivos que ofrece. } \\
\text { - Reducida contribución del turismo al desarrollo } \\
\text { económico local. } \\
\text { - No existe programa de rehabilitación de imagen } \\
\text { urbana. } \\
\text { - Generación de artículos promocionales y de } \\
\text { difusión. }\end{array}$ \\
\hline \multicolumn{3}{|r|}{ Sur } \\
\hline $\begin{array}{l}\text { Palizada, } \\
\text { Campeche }\end{array}$ & Implicación & $\begin{array}{l}\text { - Llegadas positivas de visitantes. } \\
\text { - No está identificada claramente la estacionalidad } \\
\text { del destino. } \\
\text { - Existencia de un inventario de recursos turísticos. } \\
\text { - Reducida oferta de servicios turísticos. } \\
\text { - El turismo comienza a ser una opción que } \\
\text { contribuye al desarrollo local. } \\
\text { - No se identifica el valor de la marca Pueblo Mágico } \\
\text { para la localidad. } \\
\text { - No existe igualdad de compromiso en la actuación } \\
\text { de comunidad y de autoridades. }\end{array}$ \\
\hline
\end{tabular}

Fuente: Elaboración propia a partir de SECTUR (2014b). 
Tabla 10. Ciclo de vida de pueblos mágicos inscritos en 2011

\begin{tabular}{|c|c|c|}
\hline Localidad & Fase & Características \\
\hline \multicolumn{3}{|r|}{ Golfo } \\
\hline Xico, Veracruz & Implicación & $\begin{array}{l}\text { - Llegadas de visitantes nacionales. } \\
\text { - Existen inventario de atractivos turísticos. } \\
\text { - Conservación media de los atractivos. } \\
\text { - Reducida conectividad al lugar. } \\
\text { - Reducida oferta de servicios turísticos. } \\
\text { - Limitado empleo turístico. } \\
\text { - Buen índice de satisfacción del usuario. } \\
\text { - Cambios perceptibles en la apariencia física del } \\
\text { sitio. } \\
\text { - Publicidad digital incipiente. }\end{array}$ \\
\hline \multicolumn{3}{|r|}{ Pacífico } \\
\hline $\begin{array}{l}\text { San Sebastián del } \\
\text { Oeste, Jalisco }\end{array}$ & Implicación & $\begin{array}{l}\text { - Llegadas continuas de visitantes pero reducidas. } \\
\text { - El verano es identificado como el periodo de } \\
\text { estacionalidad. } \\
\text { - Mayor número de atractivos culturales. } \\
\text { - No existe información sobre la actividad turística en } \\
\text { el desarrollo local. } \\
\text { - Suficiente oferta de servicios turísticos básicos. } \\
\text { - Reducida conectividad para el acceso al sitio. } \\
\text { - Reducida publicidad digital. }\end{array}$ \\
\hline \multicolumn{3}{|r|}{ Centro } \\
\hline $\begin{array}{l}\text { El Oro, Estado de } \\
\text { México }\end{array}$ & Desarrollo & $\begin{array}{l}\text { - Visitantes y turistas regionales de estadía corta. } \\
\text { - Reducida pero atractiva oferta de recursos turísticos } \\
\text { en su inventario. } \\
\text { - Suficiente oferta de servicios turísticos básicos y } \\
\text { complementarios. } \\
\text { - Crecimiento en la calidad de prestación de servicios } \\
\text { públicos. } \\
\text { - Parte de la economía local está ligada al turismo. } \\
\text { - Reducida conectividad al destino. } \\
\text { - Poca estacionalidad; no identificados los periodos. } \\
\text { - No hay publicidad, pero si una marca del lugar. } \\
\text { - Para la promoción se utilizan medios impresos, } \\
\text { algunas páginas web y redes sociales. }\end{array}$ \\
\hline
\end{tabular}




\begin{tabular}{|c|c|c|}
\hline $\begin{array}{l}\text { Mineral del } \\
\text { Chico, Hidalgo }\end{array}$ & Desarrollo & $\begin{array}{l}\text { - Cantidades medias de visitantes de los estados de } \\
\text { la región. } \\
\text { - Reducida estacionalidad; no identificados los } \\
\text { periodos. } \\
\text { - Amplitud en la oferta de actividades y atractivos de } \\
\text { naturaleza. } \\
\text { - Pocos atractivos de tipo cultural en su inventario. } \\
\text { - Sólo existe conectividad terrestre. } \\
\text { - Suficiente oferta de servicios turísticos básicos. } \\
\text { - Parte de la economía está ligada al sector turístico. } \\
\text { - Publicidad digital. }\end{array}$ \\
\hline
\end{tabular}

Fuente: Elaboración propia a partir de SECTUR (2014b).

Tabla 11. Ciclo de vida de pueblos mágicos inscritos en 2012

\begin{tabular}{|c|c|c|}
\hline Localidad & Fase & Características \\
\hline \multicolumn{3}{|r|}{ Norte } \\
\hline $\begin{array}{l}\text { Loreto, Baja } \\
\text { California Sur }\end{array}$ & Consolidación & $\begin{array}{l}\text { - La cantidad de turistas es mayor al total de la } \\
\text { población local en temporadas altas, pero persiste } \\
\text { afluencia de visitantes durante el año. } \\
\text { - Gran variedad de atractivos culturales y naturales. } \\
\text { - Existencia de productos turísticos diferenciados a } \\
\text { través de rutas, circuitos y actividades diversas. } \\
\text { - El turismo es una de las principales actividades } \\
\text { económicas de la localidad. } \\
\text { - Amplia oferta de servicios turísticos básicos locales y } \\
\text { de cadena, así como de servicios complementarios. } \\
\text { - Fuentes abundantes de empleo por el sector } \\
\text { turismo. } \\
\text { - Cuenta con conectividad marítima, aérea y terrestre. } \\
\text { - No existen cambios perceptibles en la } \\
\text { transformación de la imagen urbana. } \\
\text { - Publicidad digital y de alcance. }\end{array}$ \\
\hline Viesca, Coahuila & Desarrollo & $\begin{array}{l}\text { - Visitantes nacionales de la región centro y norte del } \\
\text { país. } \\
\text { - Cantidad de turistas mayor al total de la población } \\
\text { en temporadas altas. } \\
\text { - Oferta atractiva de recursos culturales en alto grado } \\
\text { de conservación. } \\
\text { - Conectividad terrestre y aérea. } \\
\text { - Reducida oferta de servicios turísticos básicos. } \\
\text { - Cambios perceptibles en la imagen urbana. } \\
\text { - Publicidad en internet. }\end{array}$ \\
\hline
\end{tabular}




\begin{tabular}{|c|c|c|}
\hline $\begin{array}{l}\text { Batopilas, } \\
\text { Chihuahua }\end{array}$ & Implicación & $\begin{array}{l}\text { - Llegadas nacionales y extranjeras positivas pero } \\
\text { lentas. } \\
\text { - Conservación de recursos de naturaleza. } \\
\text { - Alta estacionalidad. } \\
\text { - Reducida conectividad terrestre y aérea. } \\
\text { - Pocos servicios turísticos básicos y ofrecidos por la } \\
\quad \text { población local. } \\
\text { - Publicidad en internet. } \\
\text { - Imagen urbana reglamentada. }\end{array}$ \\
\hline El Rosario, Sinaloa & Implicación & $\begin{array}{l}\text { - Llegadas positivas pero lentas. } \\
\text { - Poca estacionalidad. } \\
\text { - Atractivos turísticos de tipo cultural. } \\
\text { - Conectividad reducida. } \\
\text { - Prestación de servicios turísticos por los residentes. } \\
\text { - Publicidad incipiente. } \\
\text { - Imagen urbana reglamentada. }\end{array}$ \\
\hline \multicolumn{3}{|r|}{ Pacífico } \\
\hline $\begin{array}{l}\text { Tacámbaro, } \\
\text { Michoacán }\end{array}$ & Desarrollo & $\begin{array}{l}\text { - Llegadas de visitantes positivas y en aumento pero } \\
\text { lentas. } \\
\text { - Buena oferta de atractivos de naturaleza con } \\
\text { mejores instalaciones. } \\
\text { - Reducida oferta de servicios turísticos, ofrecidos por } \\
\text { los residentes. } \\
\text { - Accesos para conectividad terrestre en mejora y } \\
\text { cercanía de terminales para conectividad aérea. } \\
\text { - Publicidad digital en impulso. } \\
\text { - Imagen urbana reglamentada. }\end{array}$ \\
\hline Jala, Nayarit & Implicación & $\begin{array}{l}\text { - Baja estacionalidad. } \\
\text { - Llegadas positivas pero lentas. } \\
\text { - Suficiencia de atractivos turísticos, pero carentes de } \\
\text { actividades. } \\
\text { - Casi nula oferta de servicios turísticos básicos. } \\
\text { - Reducida conectividad terrestre. } \\
\text { - No existen datos sobre empleo turístico. } \\
\text { - Publicidad en internet. } \\
\text { - No existe reglamentación urbana. }\end{array}$ \\
\hline \multicolumn{3}{|r|}{ Centro } \\
\hline $\begin{array}{l}\text { Metepec, Estado } \\
\text { de México }\end{array}$ & Implicación & $\begin{array}{l}\text { - Visitantes y turistas de estadía muy corta. } \\
\text { - Reducida oferta de recursos turísticos. } \\
\text { - Suficiente oferta de servicios turísticos de } \\
\text { alimentación y transporte. } \\
\text { - Calidad en la prestación de servicios públicos. } \\
\text { - Buena conectividad al destino. } \\
\text { - No hay estacionalidad } \\
\text { - Imagen urbana reglamentada. } \\
\text { - Portales de internet. }\end{array}$ \\
\hline
\end{tabular}




\begin{tabular}{|c|c|c|}
\hline $\begin{array}{l}\text { Mineral de Pozos, } \\
\text { Guanajuato }\end{array}$ & Desarrollo & $\begin{array}{l}\text { - La cantidad de turistas es mayor al total de la } \\
\text { población local, en temporadas altas. } \\
\text { - Reducida pero atractiva oferta de recursos. } \\
\text { - El turismo contribuye a la economía local. } \\
\text { - Suficiente oferta de servicios turísticos básicos. } \\
\text { - Existe conectividad terrestre. } \\
\text { - Publicidad en internet. } \\
\text { - Imagen urbana reglamentada. }\end{array}$ \\
\hline $\begin{array}{l}\text { Salvatierra, } \\
\text { Guanajuato }\end{array}$ & Implicación & $\begin{array}{l}\text { - Visitantes locales y regionales. } \\
\text { - Suficiente oferta de atractivos turísticos } \\
\text { - Existe conectividad terrestre. } \\
\text { - Calidad en la prestación de servicios públicos. } \\
\text { - Poca oferta de servicios turísticos básicos. } \\
\text { - No hay publicidad de alcance. } \\
\text { - El turismo genera poco empleo. }\end{array}$ \\
\hline $\begin{array}{l}\text { Yuriria, } \\
\text { Guanajuato }\end{array}$ & Implicación & $\begin{array}{l}\text { - Existe afluencia de visitantes nacionales y pocos } \\
\text { extranjeros. } \\
\text { - Suficiente oferta de atractivos culturales y naturales. } \\
\text { - Conectividad terrestre reducida. } \\
\text { - No hay publicidad de alcance. } \\
\text { - Reducida oferta de servicios turísticos básicos. } \\
\text { - Poco empleo en el sector turismo. } \\
\text { - No hay reglamentación para imagen urbana. }\end{array}$ \\
\hline $\begin{array}{l}\text { Chignahuapan, } \\
\text { Puebla }\end{array}$ & Desarrollo & $\begin{array}{l}\text { - Llegada de visitantes mayor a la población en } \\
\text { temporadas altas. } \\
\text { - Pocas semanas de estacionalidad pero continuas en } \\
\text { el segundo semestre del año. } \\
\text { - Riqueza de atractivos culturales y naturales. } \\
\text { - Generación de pocos productos turísticos. } \\
\text { - Crece la contribución del turismo a la economía } \\
\text { local. } \\
\text { - Prestación amplia de servicios turísticos básicos por } \\
\text { empresas locales. } \\
\text { - Buena conectividad terrestre. } \\
\text { - Publicidad digital incipiente. } \\
\text { - Imagen urbana reglamentada. }\end{array}$ \\
\hline Xicotepec, Puebla & Desarrollo & $\begin{array}{l}\text { - Llegada de visitantes nacionales un poco mayor que } \\
\text { el total de la población. } \\
\text { - Poca estacionalidad. } \\
\text { - Suficiencia en atractivos culturales y amplitud en la } \\
\text { oferta de atractivos naturales en estado medio de } \\
\text { conservación. } \\
\text { - Se han generado algunos productos turísticos. } \\
\text { - Oferta de servicios turísticos básicos locales y } \\
\text { mejora en sus instalaciones. } \\
\text { - Se considera que el turismo contribuye a la } \\
\text { economía local. } \\
\text { - Imagen urbana reglamentada. } \\
\text { - Publicidad digital incipiente. }\end{array}$ \\
\hline
\end{tabular}




\begin{tabular}{|c|c|c|}
\hline $\begin{array}{l}\text { Tequisquiapan, } \\
\text { Querétaro }\end{array}$ & Desarrollo & $\begin{array}{l}\text { - Llegada de visitantes nacionales igual o mayor que } \\
\text { el total de la población. } \\
\text { - Estacionalidad en casi la mitad del año. } \\
\text { - Riqueza cultural atractiva complementada con } \\
\text { algunos recursos de tipo natural, con alto grado de } \\
\text { conservación. } \\
\text { - Amplia oferta de empresas prestadoras de servicios } \\
\text { turísticos básicos y complementarios, destacando } \\
\text { las empresas locales. } \\
\text { - Sólo existe conectividad terrestre. } \\
\text { - La actividad turística genera un porcentaje medio } \\
\text { alto de empleo. } \\
\text { - Imagen urbana reglamentada. } \\
\text { - Publicidad en internet. }\end{array}$ \\
\hline $\begin{array}{l}\text { Nochistlán, } \\
\text { Zacatecas }\end{array}$ & Implicación & $\begin{array}{l}\text { - Estacionalidad baja. } \\
\text { - Llegada positivas de visitantes pero muy lentas. } \\
\text { - Suficiencia en recursos de tipo natural. Pocos } \\
\text { atractivos culturales en estado medio de } \\
\text { conservación. } \\
\text { - No hay un uso activo de los recursos turísticos. } \\
\text { - Sólo existe conectividad terrestre, pero es buena. } \\
\text { - Dispone de buena prestación de servicios públicos. } \\
\text { - Escasa oferta de servicios turísticos y de mala } \\
\text { calidad. Falta profesionalización en la prestación de } \\
\text { servicios. } \\
\text { - Cambios perceptibles en la apariencia física del } \\
\text { lugar. } \\
\text { - Promoción del destino prácticamente nula. }\end{array}$ \\
\hline \multicolumn{3}{|r|}{ Sur } \\
\hline $\begin{array}{l}\text { Chiapa de Corzo, } \\
\text { Chiapas }\end{array}$ & Consolidación & $\begin{array}{l}\text { - Alta afluencia de visitantes y alta estacionalidad en } \\
\text { el año. } \\
\text { - Existencia de riqueza turística natural y cultural de } \\
\text { gran atractivo. } \\
\text { - Conformación de productos turísticos como rutas o } \\
\text { circuitos } \\
\text { - Estado alto de conservación de sus recursos } \\
\text { culturales. } \\
\text { - Existen empresas turísticas locales y de cadena. } \\
\text { - Suficiencia de servicios públicos. } \\
\text { - Existe conectividad aérea y terrestre. } \\
\text { - Existe reglamentación urbana. } \\
\text { - Publicidad digital y de alcance. } \\
\text { - Alto grado de satisfacción del visitante. }\end{array}$ \\
\hline
\end{tabular}

Fuente: Elaboración propia a partir de SECTUR (2014b). 
Una vez identificadas las características de la fase del ciclo de vida de cada localidad muestreada, se exponen las Figuras 2 y 3 en las cuales se presenta un análisis concentrado de la preponderancia de dichas fases en las localidades examinadas y cómo se presenta también la situación de estas etapas por región. Al analizar el ciclo de vida en la muestra, se observa (Figura 2) que la fase de desarrollo es la que se presenta en mayor porcentaje $(43,59 \%)$, seguida con una diferencia de poco más de dos puntos por las localidades que se encuentran en fase de implicación (41,02\%). La etapa de consolidación se presenta sólo en cinco localidades, lo que representa un porcentaje tres veces menor, aproximadamente, a los porcentajes obtenidos para las otras dos etapas (12,82\%). Se observa también en la Figura 2 un porcentaje pequeño $(2,56 \%)$ correspondiente a una localidad de la muestra de la cual no se pudo identificar su etapa de vida, por no contar con la suficiente información para ello.

Figura 2. Porcentajes de las fases del ciclo de vida en los pueblos mágicos



Elaboración propia.

Con respecto al análisis realizado por región (Figura 3), los resultados exhiben que cuatro de las cinco regiones presentan localidades en etapa de consolidación, siendo la Región Pacífico la que muestra un mayor porcentaje (25\%). Las Regiones Centro y Norte tienen porcentajes en un rango del $53,33 \%$ al $66,67 \%$ de poblaciones en etapa de desarrollo y, en lo referente a la fase de implicación, todas las regiones presentan poblaciones en esta etapa en distintos porcentajes: bajos (22,22\% y $33,33 \%)$, medios ( $40 \%$ y $50 \%$ ) y altos $(100 \%)$, siendo la Región Golfo la que presenta el porcentaje mayor, ya que sus tres poblaciones de la muestra así lo exhiben. 
Figura 3. Ciclo de vida de los pueblos mágicos por regiones

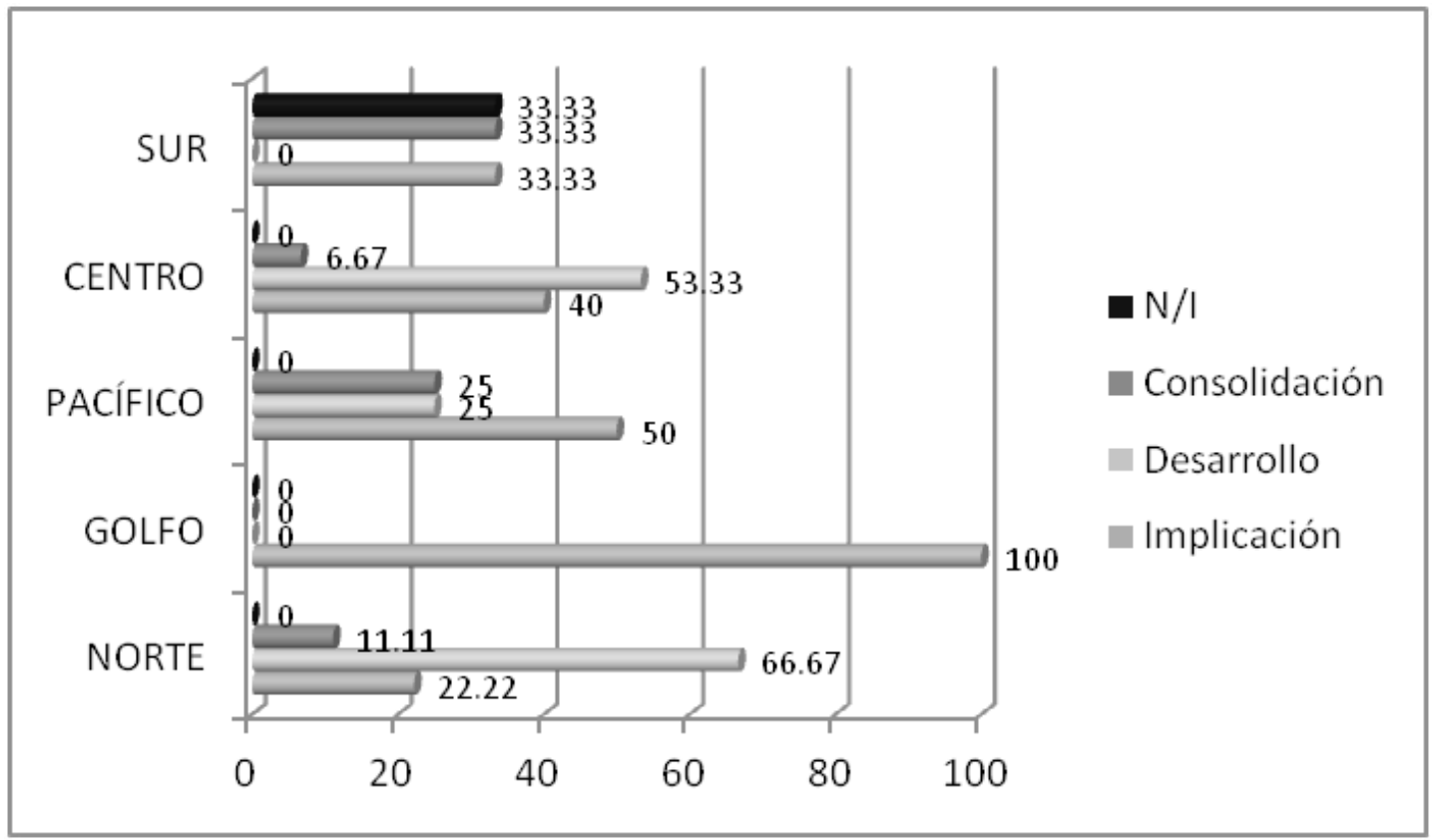

Elaboración propia.

\subsection{Estrategias competitivas en Pueblos Mágicos consolidados}

Para dar continuidad al propósito de este estudio, se presentan en la Tabla 12 las localidades identificadas en fase de consolidación y las estrategias que han desarrollado para alcanzar esta etapa, tratando de lograr con ellas una competitividad en evolución que les otorgue posicionamiento y beneficios de diversa índole como destinos turísticos. En esta misma tabla se indican las dimensiones o factores, señalados en el apartado de la metodología del estudio, con los cuales tienen relación cada una de estas estrategias. 
Tabla 12. Estrategias competitivas de pueblos mágicos consolidados

\begin{tabular}{|c|c|c|}
\hline $\begin{array}{l}\text { Pueblo } \\
\text { mágico }\end{array}$ & Estrategias & $\begin{array}{l}\text { Dimensión, factor o } \\
\text { ámbito }\end{array}$ \\
\hline \multirow{6}{*}{$\begin{array}{l}\text { Loreto, Baja } \\
\text { California Sur } \\
\text { Región Norte } \\
\text { Año de } \\
\text { Inscripción: } \\
2012\end{array}$} & $\begin{array}{l}\text { - Medición de índices de satisfacción del usuario para } \\
\text { planificación y toma de decisiones. }\end{array}$ & - Consumidores \\
\hline & $\begin{array}{l}\text { - Concentración de capital humano capacitado como } \\
\text { fuerza laboral que brinde servicios de calidad. }\end{array}$ & - Factor humano \\
\hline & $\begin{array}{l}\text { - Vinculación con instituciones de educación superior } \\
\text { para investigación sobre prevención social y seguridad } \\
\text { local. }\end{array}$ & $\begin{array}{l}\text { - Investigación } \\
\text { - Gestión }\end{array}$ \\
\hline & $\begin{array}{l}\text { - Creación de productos turísticos diferenciados mediante } \\
\text { el aprovechamiento de la riqueza de atractivos } \\
\text { culturales y naturales del lugar. }\end{array}$ & $\begin{array}{r}\text { - Atractivos } \\
\text { esenciales }\end{array}$ \\
\hline & $\begin{array}{l}\text { - Uso práctico de la tecnología para promoción efectiva y } \\
\text { de alcance y para generar otros canales de distribución. }\end{array}$ & $\begin{array}{l}\text { - Tecnología } \\
\text { - Marketing Mix }\end{array}$ \\
\hline & $\begin{array}{l}\text { - Delineación de planes estratégicos y operativos para } \\
\text { potencializar el turismo. }\end{array}$ & - Gestión \\
\hline \multirow{5}{*}{$\begin{array}{l}\text { Pátzcuaro, } \\
\text { Michoacán } \\
\text { Región } \\
\text { Pacífico } \\
\text { Año de } \\
\text { Inscripción: } \\
2002\end{array}$} & $\begin{array}{l}\text { - Ampliación de infraestructura vial, estacionamientos y } \\
\text { sanitarios. }\end{array}$ & $\begin{array}{l}\text { - Recursos de } \\
\text { soporte } \\
\text { - Gestión } \\
\end{array}$ \\
\hline & $\begin{array}{l}\text { - Brindar subsidios para acciones de capacitación, } \\
\text { consultoría y certificación en empresas turísticas del } \\
\text { destino. }\end{array}$ & - Factor humano \\
\hline & $\begin{array}{l}\text { - Modernización de áreas adecuadas y necesarias para el } \\
\text { desarrollo del turismo. }\end{array}$ & $\begin{array}{l}\text { - Recursos de } \\
\text { soporte }\end{array}$ \\
\hline & $\begin{array}{l}\text { - Rescate, restauración y mantenimiento permanente de } \\
\text { edificios antiguos como atractivos culturales. }\end{array}$ & $\begin{array}{l}\text { - } \text { Atractivos } \\
\text { esenciales } \\
\text { - } \text { Recursos de } \\
\quad \text { soporte } \\
\text { - } \\
\text { Sostenibilidad. }\end{array}$ \\
\hline & $\begin{array}{l}\text { - Vinculación entre dependencias gubernamentales } \\
\text { para obtención de presupuesto para promoción y para } \\
\text { proyectos de señalética. }\end{array}$ & $\begin{array}{l}\text { - Gestión } \\
\text { - Marketing Mix }\end{array}$ \\
\hline
\end{tabular}




\begin{tabular}{|c|c|c|}
\hline \multirow{6}{*}{$\begin{array}{l}\text { Taxco, } \\
\text { Guerrero } \\
\text { Región } \\
\text { Pacífico } \\
\text { Año de } \\
\text { Inscripción: } \\
2002\end{array}$} & - Mejoramiento de imagen urbana y espacios públicos. & $\begin{array}{l}\text { - Recursos de } \\
\text { soporte }\end{array}$ \\
\hline & - Regularización del comercio semifijo y ambulante. & - Gestión \\
\hline & $\begin{array}{l}\text { - Desarrollo de programas de conservación, rehabilitación } \\
\text { y equipamiento de sitios de interés turístico. }\end{array}$ & $\begin{array}{l}\text { - } \text { Atractivos } \\
\text { esenciales } \\
\text { - } \text { Recursos de } \\
\quad \text { soporte } \\
\text { - } \text { Sostenibilidad. }\end{array}$ \\
\hline & $\begin{array}{l}\text { - Rehabilitación, infraestructura, equipamiento y apoyo a } \\
\text { sistemas y materiales de información turística. }\end{array}$ & $\begin{aligned} \text { - } & \text { Tecnología } \\
\text { - } & \text { Recursos de } \\
& \text { soporte } \\
\text { - } & \text { Marketing Mix }\end{aligned}$ \\
\hline & - Rescate y puesta en valor del patrimonio. & $\begin{array}{l}\text { - } \text { Atractivos } \\
\text { esenciales } \\
\text { - } \text { Recursos de } \\
\text { soporte } \\
\text { - } \text { Sostenibilidad. }\end{array}$ \\
\hline & $\begin{array}{l}\text { - Desarrollo de productos por innovación y } \\
\text { diferenciación. }\end{array}$ & $\begin{aligned} & \text { - } \text { Atractivos } \\
& \text { esenciales } \\
& \text { - } \text { Gestión } \\
& \text { - } \text { Marketing Mix } \\
&\end{aligned}$ \\
\hline \multirow{6}{*}{$\begin{array}{l}\text { Dolores } \\
\text { Hidalgo, } \\
\text { Guanajuato } \\
\text { Región Centro } \\
\text { Año de } \\
\text { Inscripción: } \\
2002\end{array}$} & $\begin{array}{l}\text { - Mejora y unificación de imagen urbana. } \\
\text { - Desarrollo y mejora de infraestructura pública por } \\
\text { etapas. } \\
\text { - Regularización del comercio semifijo y ambulante. }\end{array}$ & $\begin{array}{l}\text { - Recursos de } \\
\text { soporte } \\
\text { - Gestión. }\end{array}$ \\
\hline & $\begin{array}{l}\text { - Desarrollo de nuevos productos por diferenciación y } \\
\text { diversificación. }\end{array}$ & $\begin{array}{l}\text { - } \text { Atractivos } \\
\text { esenciales } \\
\text { - } \text { Marketing Mix } \\
\end{array}$ \\
\hline & $\begin{array}{l}\text { - Vinculación entre dependencias gubernamentales para } \\
\text { implementar proyectos de señalética. }\end{array}$ & - Gestión \\
\hline & $\begin{array}{l}\text { - Desarrollo de programas de conservación, rehabilitación } \\
\text { y equipamiento de sitios de interés turístico. }\end{array}$ & $\begin{aligned} \text { - } & \text { Atractivos } \\
& \text { esenciales } \\
\text { - } & \text { Recursos de } \\
& \text { soporte } \\
\text { - } & \text { Sostenibilidad. }\end{aligned}$ \\
\hline & $\begin{array}{l}\text { - Generación de proyectos efectivos de promoción y } \\
\text { comercialización del destino. }\end{array}$ & $\begin{array}{l}\text { - Investigación } \\
\text { - Marketing Mix } \\
\end{array}$ \\
\hline & $\begin{array}{l}\text { - Participación incluyente de la ciudadanía en desarrollo } \\
\text { de propuestas de productos turísticos. } \\
\text { - Generación de ideas para nuevos negocios PyMES. } \\
\text { - Desarrollo por etapas de programas de cultura turística. }\end{array}$ & $\begin{array}{l}\text { - Gestión } \\
\text { - Factor humano }\end{array}$ \\
\hline
\end{tabular}


La consolidación turística en los territorios que conforman el Programa Pueblos Mágicos (México). Un análisis de sus estrategias competitivas

\begin{tabular}{|c|c|c|}
\hline \multirow{6}{*}{$\begin{array}{l}\text { Chiapa de } \\
\text { Corzo, Chiapas } \\
\text { Región Sur } \\
\text { Año de } \\
\text { Inscripción: } \\
2012\end{array}$} & $\begin{array}{l}\text { - Unificación y mejora de imagen urbana y mejoramiento } \\
\text { de espacios públicos por etapas. }\end{array}$ & $\begin{array}{l}\text { - Recursos de } \\
\quad \text { soporte } \\
\text { - Gestión }\end{array}$ \\
\hline & $\begin{array}{l}\text { - Desarrollo de inversión en infraestructura para servicios } \\
\text { públicos. }\end{array}$ & $\begin{array}{l}\text { - Recursos de } \\
\text { soporte }\end{array}$ \\
\hline & - Rescate y puesta en valor del patrimonio. & $\begin{array}{l}\text { - } \text { Atractivos } \\
\text { esenciales } \\
\text { - Recursos de } \\
\quad \text { soporte } \\
\text { - Sostenibilidad. }\end{array}$ \\
\hline & $\begin{array}{l}\text { - Desarrollo de productos por innovación y } \\
\text { diferenciación. }\end{array}$ & $\begin{aligned} \text { - } & \text { Atractivos } \\
& \text { esenciales } \\
\text { - } & \text { Gestión } \\
\text { - } & \text { Marketing Mix }\end{aligned}$ \\
\hline & - Capacitación de guías de turistas. & - Factor humano \\
\hline & - Desarrollo paulatino de programas de cultura turística. & $\begin{array}{l}\text { - Gestión } \\
\text { - Factor humano }\end{array}$ \\
\hline
\end{tabular}

Fuente: Elaboración propia a partir de SECTUR (2014b).

Los resultados de la Tabla 12 presentan un total de 33 estrategias identificadas en los cinco Pueblos Mágicos en etapa de consolidación. Algunas de éstas se refieren al mismo factor competitivo, sólo presentando diferencias, de un destino a otro, en su planteamiento.

La Figura 4 presenta las dimensiones o ámbitos en los que mayormente se ha centrado la creación de estrategias para estos Pueblos Mágicos, pudiéndose observar que las dimensiones que destacan en orden de importancia por la cantidad de estrategias desarrolladas en ellas son: Gestión con un total de 13 estrategias, Recursos de soporte, con 12, Recursos y atractivos esenciales, con 9, Marketing Mix, con 7 y en igualdad de cantidad, con 5, los ámbitos de Factor Humano y Sostenibilidad. 
Figura 4. Ámbitos de competitividad relevantes en el desarrollo de estrategias en la consolidación de pueblos mágicos

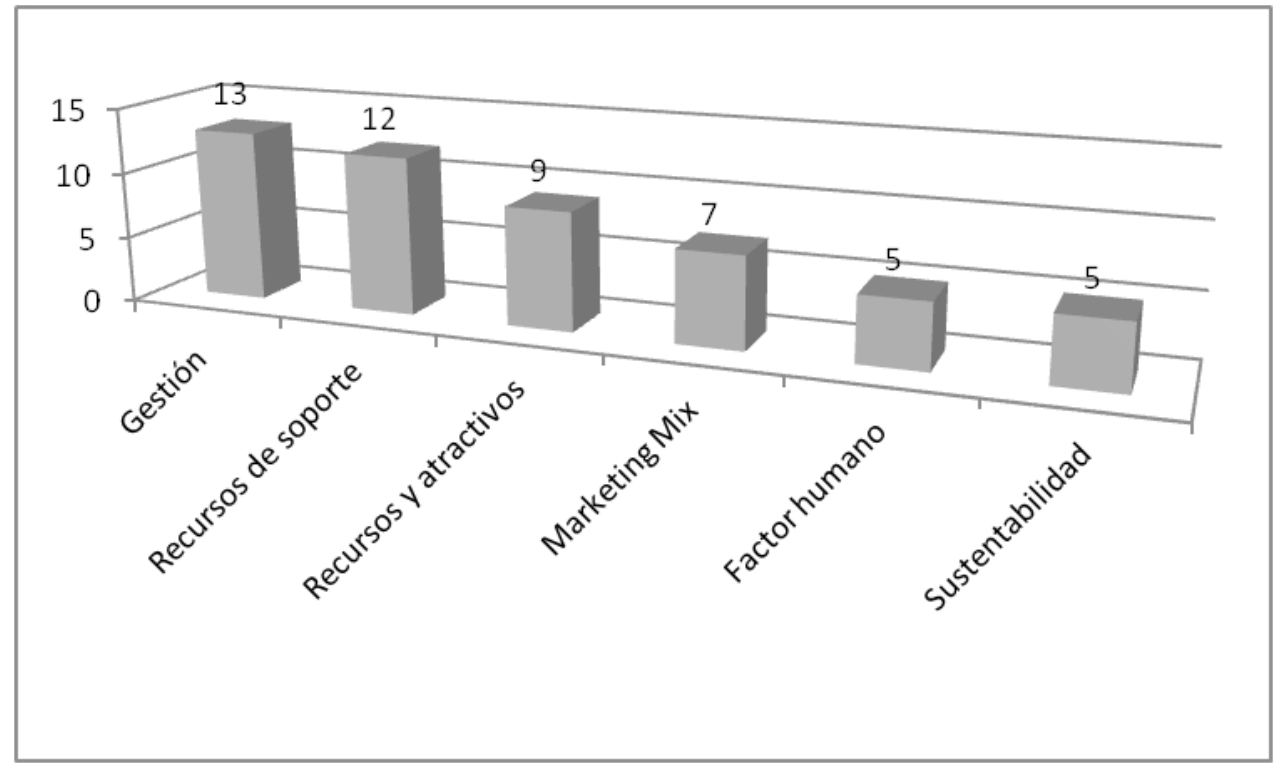

Elaboración propia.

Los resultados analizados permiten realizar algunas reflexiones como puntos de discusión. Establecer la evolución del ciclo de vida de un destino turístico requiere de la determinación de características muy concretas que faciliten la objetividad para apuntar las etapas que éste va teniendo a lo largo de su existencia.

El conocer la prosperidad turística de un destino a través de las llegadas de visitantes por períodos (Butler, 1980) es, en el presente, sólo un punto de partida para determinar en qué grado avanza dicho destino, ya que, en la actualidad, existe detrás de esa cantidad de viajeros que arriban al lugar y de esa bonanza turística del sitio, una dinámica integral de las peculiaridades que forman parte de los componentes de un destino turístico (Valls, 2004), la cual va a influir en la decisión de elegir tal o cual destino y, en consecuencia, influirá también en el incremento de la llegada de visitantes e, incluso, en la fidelización de los que ya conocen el lugar.

Un destino turístico irá creciendo y fortaleciéndose en su existir en la medida en que desarrolle estrategias y condiciones propicias para ser competitivo y enfrentarse a su competencia real o potencial. La llegada de visitantes a un destino turístico está respaldada por la competitividad que éste posee, es decir, por la productividad (Porter, 2003) con que ha sabido utilizar sus recursos y por el valor añadido (Ritchie y Crouch, 2000) que ha sido capaz de crear para responder con calidad a las necesidades de los demandantes, a diferencia de otros destinos que también pudieron haberlo hecho.

Esa productividad y ese valor añadido pueden introducirse y afianzarse a partir de la generación de estrategias que permitan vigorizar diversos aspectos que marcan la diferencia entre uno y otro lugar. No deben ser estrategias improvisadas, sino diseñadas tomando como referencia la variada cantidad de modelos de competitividad que señalan justamente 
los factores sobre los cuales necesariamente deben apuntar los esfuerzos de crecimiento que induzcan al desarrollo y a la consolidación de un destino turístico.

Dado que la muestra fue determinada con un nivel de confianza del $90 \%$, las inferencias que de ella se hagan sobre la población, tendrán ese mismo nivel de confianza.

\section{CONCLUSIONES}

Muchos destinos son gestionados bajo la ausencia de planes y programas, en los que siquiera se plasme la mínima directriz de actuación que lleve a generar una vida "saludable" para la población dentro del ámbito turístico, es decir, una línea de trabajo que apoye a crear una armonía, entre la pertenencia de los recursos naturales y culturales con los que cuenta una comunidad y que forman parte de su patrimonio como grupo social y, el uso y difusión que se hace de estos, como atractivos que motivan desplazamientos y realización de actividades por parte de personas que visitan el lugar en calidad de turistas.

Son ya más de una centena de localidades que han recibido el nombramiento Pueblo Mágico y buscar proyectarlas bajo el nombre de esta marca implica contar con una gestión apoyada en una planificación que tenga en cuenta la fuerte tendencia actual de la competitividad, la cual impactará en el curso de vida de cada una de ellas.

El propósito inicial de este estudio fue identificar la fase del ciclo de vida en la que se encuentran las localidades inscritas en este Programa Federal, para después delimitar, tanto las estrategias competitivas que las poblaciones consolidadas han implementado, así como los ámbitos o factores con los que esas estrategias están vinculadas. Para ello, los Diagnósticos de Competitividad y Sustentabilidad Turística de los Pueblos Mágicos, aportaron información valiosa que permitió, por un lado, definir con mayor acierto las características de cada localidad y determinar con la mejor objetividad posible su trayectoria de vida en el campo del turismo y, por otro, identificar la cantidad y tipo de estrategias que las localidades consolidadas han utilizado.

Ciertamente, los resultados permiten ver cómo localidades que aún no han cumplido siquiera cinco años de adscripción al programa, ya han alcanzado una etapa de consolidación que buscan mantener y a la cual han llegado en poco tiempo por la implementación de estrategias diseñadas en torno a factores clave que influyen en el éxito y posicionamiento de ese territorio como destino turístico. Lo mismo ha sucedido con algunos territorios que recibieron su nombramiento en los inicios de este programa federal: son localidades que, teniendo casi quince años con el nombramiento como Pueblos Mágicos, no se han detenido en su crecimiento y han buscado aquellas estrategias que les permitan sobresalir, ya no sólo entre la competencia, cada vez mayor, con poblaciones del mismo programa, sino con destinos de otro tipo, pero cercanos a ellas.

Por tanto, la hipótesis propuesta para esta investigación se ha comprobado, al llegar a establecerse que localidades identificadas en una fase de consolidación dentro de su ciclo de vida, tienen documentadas e implementadas varias estrategias relativas a diversos ámbitos establecidos en distintos modelos de competitividad, que les han permitido responder a las expectativas del turista y mantenerse en la oferta del mercado nacional turístico. 


\section{REFERENCIAS BIBLIOGRÁFICAS}

Andrades, L., Sánchez, M. y Pulido, J.I. (2013). Differentiating Competitiveness through Tourism Image Assessment: An Application to Andalusia (Spain). Journal of Travel Research, 52(1), 68-81.

Amaya, C.M., Conde, E.M. y Covarrubias, R. (2008). La competitividad turística: imperativo para Manzanillo, Colima. Teoría y Praxis, 5, 17-32.

Ávila, R. y Barrado, D. A. (2005). Nuevas tendencias en el desarrollo de destinos turísticos: marcos conceptuales y operativos para su planificación y gestión. Cuadernos de Turismo, 15, 27-44.

Blanke, J. y Chiesa, T. (2007). Índice de Competitividad en Viajes y Turismo. Ginebra: Foro Económico Mundial.

Bosch, R. (1998). Turismo y Medio Ambiente. Madrid: Editorial Universitaria Ramón Areces.

Buhalis, D. (2000). Marketing the competitive destination of the future. Tourism Management, 21(1), 97-116.

Butler, R. (1980). The concept of a tourist area cycle of evolution: implications for management of resources. The Canadian Geographer, Vol. 24, 5-12.

Covarrubias, R., Vargas, A. y Rodríguez, I.M. (2010): Satisfacción de residentes con el desarrollo de la actividad turística en los pueblos mágicos de México: un indicador de competitividad. Casos de Comala en Colima y de Real de Asientos en Aguascalientes. Gestión Turística, 14, 33-54.

Crouch, G. I. y Ritchie E, J. B. (1999). Tourism, Competitiveness and Societal Prosperity. Journal of Business Research, 44, 137-152.

Digance, J. (1996). Life Cycle Model. Research Notes and Reports, 452-456.

Dwyer, L., Forsyth, P. y Rao, P. (2000). The price competitiveness of travel and tourism: a comparison of 19 destinations. Tourism Management, 21, 9-22.

Dwyer, L. y Kim, C. (2003). Destination Competitiveness: determinants and indicators. Current Issues in Tourism, 5(6), 369-414.

Ekinci, Y. y Hosany, S. (2006). Destination Personality: an application of brand personality to tourism destination. Journal of Travel Research, 45, 127-140.

Enright, M. J. y Newton, J. (2005). Determinants of Tourism Destination Competitiveness in Asia Pacific: Comprehensiveness and Universality. Journal of Travel Research, 43, 339-350.

García, J. (2011). Cuenca: un destino turístico consolidado. Cuadernos de Turismo, 27, 403-418.

García, J. y Pulido, J. I (2015). Creacity, una propuesta de índice para medir la creatividad turística. Aplicación en tres destinos urbano-culturales españoles. Revista de Estudios Regionales, 103, 69-108.

Genest, J. y Legg, D. (2003). Premier-ranked tourist destinations: development of a framework for analysis and its self-guided workbook. Ontario: Turismo del Gobierno de Canadá.

Gonçalves-Gândara, J.M., Domareski, T., Chim, A. y Biz, A. (2013). El ciclo de vida y el posicionamiento competitivo de los productos turísticos de Foz de Iguaçu desde la perspectiva de los actores locales. Investigaciones Turísticas, Vol. 6, 1-26.

González, R.C. y Mendieta, M.D. (2009). Reflexiones sobre la Conceptualización de la Competitividad de Destinos Turísticos. Cuadernos de Turismo, 23, 111-128.

Ibáñez, R. (2011). Diagnóstico de la calidad y competitividad del sector turístico en México. Cuadernos de Turismo, 28, 121-143. 
Jiménez, P. y Aquino, F.K. (2012). Propuesta de un modelo de competitividad de destinos turísticos. Estudios y Perspectivas en Turismo, Vol. 21 (4), 977-995.

Jiménez, M.H. (2006). Modelo de competitividad empresarial. Umbral Científico, 9, 115-125.

Kotler, P. (1994). Mercadotecnia de localidades. México: Diana Editores.

Loredo, J. L. (2012). Pueblos Mágicos: entre el simulacro y la realidad. Revista de Arquitectura, Urbanismo y Ciencias Sociales, Vol. III (1), 1-19.

Mazaro, R. (2007). Factores determinantes de competitividad para destinos turísticos en el marco de la sostenibilidad. Observatorio de Innovación de Turismo, Vol. 2(1), 1-16.

Mazaro, R. y Varzin, G. (2008). Modelos de competitividad de destinos turísticos en el marco de la sostenibilidad. Revista de Administración Contemporánea, Vol. XII (3), 789-809.

Montaño, A., Pérez, J.C. y De la O, V. (2014). Reposicionamiento para destinos turísticos consolidados: el caso de Los Cabos, México. Cuadernos de Turismo, 33, 271-295.

Muñoz, A. (2002). La Imagen de un Destino Turístico: Concepto e Instrumentalización. Una Aproximación a la Comunicación como Instrumento de Política. BURJC Digital, 1-48. Recuperado de http://hdl.handle.net/10115/2806

OMT (2016). Barómetro OMT del turismo mundial, Vol. 14. Madrid: Organización Mundial del Turismo. Recuperado de http://mkt.unwto.org/barometer/may-2016-volume-14

OMT (2017). El turismo: un fenómeno económico y social. Organización Mundial del Turismo. Recuperado de http://www2.unwto.org/es/content/por-que-el-turismo

Oreja, J. R., Parra, E. y Yanes, V. (2008). The sustainability of island destination: Tourism area life cycle and teleological perspectives, the case of Tenerife. Tourism Management, 29, 53-65.

Oyarzún, E. y Szmulewicz, P. (2009). Fortalecimiento de los Destinos Turísticos. Gestión Turística, Vol. 1(4), 93-102.

Pedro, A. (2015). El reto de la competitividad y sostenibilidad para los destinos turísticos. Innovación más Desarrollo, Vol. IV (7), 32-62.

Pérez, C. y Páez, A. I. (2014). El turismo de eventos y reuniones en destinos turísticos maduros: Un pilar para la reconversión del producto turístico de Puerto de la Cruz (Tenerife). Investigaciones Turísticas, 7, 102-135.

Pike, S. (2009). Destination brand positions of a competitive set of near-home destinations. Tourism Management, 30, 857-866.

Porter, M.E. (1980). Estrategia competitiva. México: CECSA.

Porter, M.E. (1990). The Competitive Advantage of Nations. Harvard Business Review, march/ april, 71-91.

Porter, M.E. (2003). Ser Competitivo. Madrid: DEUSTO Ediciones.

Puccio, H. y Grana, N. (2008). La innovación como requisito para la competitividad turística. Gestión Turística, 10, 59-76.

Ritchie, J.R.B. y Crouch, G.I. (2000). The competitive destination: A sustainability perspective. Tourism Management, 21, 1-7.

Ritchie, J.R.B. y Crouch, G.I. (2003). The competitive destination. Wallingford: CAB International Publishing.

Rodríguez, I.M. y Pulido, J.I. (2010). Factores condicionantes de la sostenibilidad como una dimensión estratégica del desarrollo turístico mexicano. Cuadernos de Turismo, 25, 125-146. 
SECTUR (2001). Pueblos Mágicos. Reglas de Operación. México: Secretaría de Turismo.

SECTUR (2014a). Acuerdo por el que se establecen los Lineamientos Generales para la incorporación y permanencia al Programa Pueblos Mágicos. México: Secretaría de Turismo. Diario Oficial de la Federación.

SECTUR (2014b). Diagnósticos de Competitividad y Sustentabilidad de los Pueblos Mágicos. México: Secretaría de Turismo. Recuperado de http://www.sectur.gob.mx/ pueblos-magicos

SEGOB (2013). Plan Nacional de Desarrollo 2013-2018. México: Secretaría de Gobernación. Recuperado de http://pnd.gob.mx/

Shaadi, R.M., Pulido, J.I. y Rodríguez, I.M. (2016). El producto turístico en los Pueblos Mágicos de México. Un análisis crítico de sus componentes. Revista de Estudios Regionales, 108, 87-120.

Soares, J., Gândara, J. e Ivars, J. (2012). Indicadores para analizar la evolución del ciclo de vida de los destinos turísticos litorales. Investigaciones Turísticas, 3, 19-38.

Valls, J. (2004). Gestión de destinos turísticos sostenibles. España: ESIC, Gestión 2000.

Velázquez, M. A. (2013). La formulación de las políticas públicas de turismo en México. El caso del programa federal "Pueblos Mágicos" 2001-2012. Diálogos Latinoamericanos, 21, 89-110.

Vera, J.F. (1994). El modelo turístico del Mediterráneo español: agotamiento y estrategias de reestructuración. Papers de Turisme, 14-15, 131-148.

Vera, J.F. y Baños, C. J. (2010). Renovación y reestructuración de los destinos turísticos consolidados del litoral: las prácticas recreativas en la evolución del espacio turístico. Boletín de la Asociación de Geógrafos Españoles, 53, 329-353. 